\title{
EVOLUCIÓN DE LOS PLAZOS DE PAGO DE LOS AGENTES ECONÓMICOS EN ESPAÑA: ¿CÓMO HA AFECTADO LA LEY CONCURSAL 3/2004?
}

\author{
Agustín V. RUIZ VEGA \\ CATEDRÁtico de COMERCIALIZACIÓN E INVESTIGACIÓN DE MERCADOS \\ UNIVERSIDAD DE LA RIOJA
}

SUMARIO: I. Introducción. II. El crédito comercial: Breve justificación teórica de su existencia. III. El período medio de maduración: Concepto económico esencial para medir y gestionar los plazos de pago a proveedores. IV. Pago a proveedores por las empresas comerciales minoristas. V. Plazos de pago de los restantes agentes económicos. VI. Conclusiones. VII. Bibliografía.

RESUMEN: La promulgación de la Ley 3/2004 ha influido de forma desigual sobre los plazos de pago de las empresas españolas. El comercio minorista ha reducido el período de tiempo de pago a sus proveedores mientras que el resto de los agentes económicas han tenido aumentos de dichos plazos de pago, los cuales han sido especialmente intensos en las empresas del sector de construcción y por parte de las Administraciones Públicas.

PALABRAS CLAVE: Distribución comercial, aplazamiento de pago a proveedores.

KEYWORDS: Criminal law, prisons, prisoners, discrimination, social problems.

\section{Introducción}

La relación comercial entre los diversos agentes económicos, tanto públicos como privados, está basada en el crédito comercial. Para justificar este punto de partida basta recordar, a título de ejemplos paradigmáticos, el desarrollo de diferentes formas de endeudamiento que han tenido como consecuencia directa la expansión de la cifra de ventas en todas las actividades económicas: (a) respecto a las unidades familiares un instrumento de crédito comercial con una larga trayectoria histórica ha sido la letra de cambio o, por indicar alguno más reciente, las tarjetas de crédito; (b) respecto a las empresas y administraciones públicas, las facturas, albaranes, certificados de obra y otros documentos similares sirven para acreditar la existencia de un derecho de cobro vinculado a una adquisición de productos por los clientes.

La evolución del crédito comercial ha estado tradicionalmente condicionada por la existencia de un riesgo de impago que ha sido regulado en el marco jurídico. No obstante, 
en España las empresas han puesto de manifiesto la insuficiencia de dicha regulación legal puesto que recuperar el dinero adeudado por la clientela morosa es cada vez más costoso e incierto. Además, han subrayado la importancia relativa de un aspecto del crédito comercial acerca del cual existía un cierto vacío legal: el alargamiento extremo de los plazos de cobro que afectaba a clientes solventes que así lo estipulaban en los pertinentes documentos contractuales. Tal como refleja la Tabla I, los plazos de pago eran mucho mayores en los países latinos -con España e Italia a la cabeza- aunque debe precisarse que dicho alargamiento suele terminar con el pago de la deuda; en definitiva, el aumento del plazo de pago no estaba directamente relacionado con la potencial morosidad del crédito comercial concedido.

TABLA I: PlAZOS DE PAGO EN LOS PRINCIPALES PAÍSES DE LA UNIÓN EUROPEA

\begin{tabular}{|c|c|c|c|}
\hline Estado & 1994 & 2000 & 2004 \\
\hline España & 85,6 & $83, \mathrm{I}$ & 82,6 \\
\hline Italia & 85,4 & 87,2 & $8 \mathrm{I}, 7$ \\
\hline Francia & 61,5 & 62,8 & 60,4 \\
\hline Holanda & 20,9 & 27,8 & 40,2 \\
\hline Alemania & 28,7 & 27,6 & 23,4 \\
\hline Media 6 países UE & $6 \mathrm{I}, \mathrm{O}$ & 68,2 & 67,3 \\
\hline
\end{tabular}

Fuente: Eurostat

La Directiva 2000/35/CE surgió para dar respuesta a los dos problemas económicos antes citados. Primero, se indica que la morosidad es la segunda causa de quiebras e insolvencias de empresas en el ámbito geográfico de la Unión Europea (en adelante UE), afectando especialmente a las pequeñas y medianas empresas ${ }^{\mathrm{I}}$. Segundo, el plazo de pago para el conjunto de todos los países que integran la UE era de 58 días durante el año I999 pero dicho plazo era sustancialmente superior en los países del Sur: 94 días en Grecia, 9I días en Portugal, 87 días en Italia y 83 días en España (cuarto país con mayor alargamiento del plazo de pago dentro del ranking comunitario). Por el contrario, en los países nórdicos el plazo de pago era el menor de la UE: 27 días en Noruega, 29 días en Finlandia y 32 días en Suecia. La Directiva arriba citada fue aprobada el 29 de junio de 2000 estableciendo medidas de lucha contra la morosidad en las operaciones comerciales; dicha Directiva dejaba un plazo máximo de dos años para que fuera adaptada e incorporada a la legislación nacional, siendo la fecha tope de adaptación el 8 de agosto de 2002.

España incorporó tardíamente ${ }^{2}$ la Directiva anterior al ordenamiento jurídico nacional pues lo hizo mediante la Ley 3/2004 de 29 de diciembre (que entró en vigor a 3I de diciembre de 2004). El objetivo de la Ley 3/2004 era doble (art. I):

${ }^{1}$ Este hecho ya fue constatado anteriormente en el Informe sobre los retrasos de pago en las transacciones comerciales (Comisión Europea, 9 de julio de I997).

${ }^{2}$ De hecho la Federación española de Industrias de la Alimentación y Bebidas (FIAB) planteó un recurso ante el Tribunal de Justicia europeo por incumplimiento del estado español, el cual fue resuelto favorablemente durante 2005 . 
$\left.\mathrm{I}^{\mathrm{O}}\right)$ Reducir la morosidad del crédito comercial.

$2^{\circ}$ ) Disminuir el abuso en la fijación de plazos de pago (casi 83 días en 2004).

El ámbito de aplicación de la Ley 3/2004 son los pagos efectuados como contraprestación de las operaciones comerciales realizadas entre empresas y/o las Administraciones Públicas (art. 2). Sintéticamente, la Ley estaba dividida en tres grandes bloques ${ }^{3}$ : regulación de los plazos de pago, fijación de mecanismos punitivos derivados de la morosidad y regulación de las cláusulas abusivas en las relaciones contractuales.

Respecto a la regulación de los plazos de pago (art. 4 de la Ley 3/2004) como regla general se aplica la libertad de pactos lo cual supone el reconocimiento de la autonomía privada. No obstante, se fija como régimen legal subsidiario un límite de 30 días que se computarán a partir de la fecha de entrega de la recepción del bien. Sin embargo, existen dos excepciones al plazo anterior. De un lado, las Administraciones públicas han de abonar el pago dentro de los 60 días siguientes a la fecha de expedición de las certificaciones de obras o de los documentos que acrediten la realización total o parcial del contrato. De otro lado, existe un régimen específico para las empresas detallistas ${ }^{4}$ según el cual éstas, como norma general, han de realizar el pago de sus compras antes de 30 días a partir de la fecha de entrega de las mercancías (art. I7.I.) que, de acuerdo con la disposición transitoria segunda de la Ley 7/I996, debería entrar en vigor a partir del I de julio de 2006. Posteriormente, el RD 367/2005, de 8 de abril, al desarrollar la Ley anterior fija en 30 días el plazo máximo de pago para los productos frescos y perecederos; para los restantes productos alimentarios y de gran consumo el plazo máximo se establece en 60 días salvo pacto expreso entre las partes, en cuyo caso podría alargarse no más de 90 días y siempre con compensación económica por la demora en el pago.

En relación con el segundo bloque de la Ley 3/2004 (arts. 5 a 8), ésta establece el reconocimiento automático de intereses de demora, siempre que la causa sea imputable al deudor sin que sea necesario un requerimiento legal. Además, el tipo de interés de demora será el fijado en el contrato o, en su defecto, el fijado por el Banco Central Europeo al inicio de cada semestre añadido un diferencial o spread de 7 puntos. La Tabla 2 muestra la evolución del tipo de demora desde la fecha de entrada en vigor de la ya mencionada Ley $3 / 2004$.

${ }^{3}$ Dado el objetivo del presente artículo no se hace mención a las cláusulas de reserva de dominio a favor de vendedor en virtud de las cuales el vendedor conserva la titularidad de los bienes hasta el pago total del precio estipulado en la transacción económica. Adicionalmente, el vendedor puede subrogar en un tercero este derecho si así lo considera pertinente.

${ }^{4}$ Ley 7/1996, de I5 de enero, sobre ordenación del comercio minorista. 
TABlA 2: EVOLUCiÓN TEMPORAL DEL TIPO DE DEMORA

\begin{tabular}{|c|c|c|}
\hline Año & Semestre & Interés de demora \\
\hline 2005 & Enero-Junio & $9,09 \%$ \\
\hline \multirow{2}{*}{2006} & Julio-Diciembre & $9,05 \%$ \\
\hline & Enero-Junio & $9,25 \%$ \\
\hline 2007 & Julio-Diciembre & $8,83 \%$ \\
\hline \multirow{2}{*}{2008} & Enero-Junio & I0,58 \% \\
\hline & Julio-Diciembre & II, 07 \% \\
\hline & Enero-Junio & II,20\% \\
\hline
\end{tabular}

Fuente: Dirección General del Tesoro y Política Financiera

Adicionalmente, se reconoce el derecho del acreedor a recibir una indemnización por costes de cobro a fin de compensar el esfuerzo económico resultante de recuperar la deuda impagada; para ello, el acreedor debe acreditar los costes y gastos derivados de la mora. La cuantía de la indemnización será el I5\% del montante de la deuda cuando ésta supere los 30.000 euros; si la deuda es inferior a dicha cantidad, aplicando el principio de proporcionalidad, el límite de indemnización será el propio importe de la deuda.

Por último, en relación con la regulación de las cláusulas abusivas en las relaciones contractuales, el art. 9 de la Ley 3/2004 dispone que, salvaguardando el principio general de libertad contractual, serán nulas las cláusulas pactadas entre las partes cuando tengan un contenido abusivo en perjuicio del acreedor y, especialmente, respecto al plazo de pago como a los tipos de interés aplicables a los retrasos en el pago de las cantidades adeudadas. El indicador de cláusula abusiva mencionado significa que el acreedor consigue liquidez adicional al acreedor a expensas del proveedor sin que existan causas objetivas que lo justifiquen.

En definitiva, la situación respeto al cobro de deudas comerciales en España es deficiente por dos motivos que ha sido tradicionalmente atribuida a dos causas: la deficiente regulación del derecho mercantil y del derecho procesal ${ }^{5}$ y la escasa productividad de los juzgados. $^{6}$ La consecuencia final ha sido que ciertos deudores con un alto poder de negociación (principalmente las grandes empresas de distribución comercial y las Administraciones Públicas) se comportan de forma oportunista alargando los plazos de pago a sus proveedores y, por tanto, encareciendo la contratación.

Por todo lo anterior, el objetivo principal del presente trabajo es analizar la influencia que ha tenido la promulgación y aplicación de la Ley 3/2004 sobre los plazos de pago entre los diferentes agentes económicos afectados. Para ello, el resto del artículo ha sido dividido en varios apartados. Primero, desde una perspectiva económica se realizará

\footnotetext{
${ }^{5}$ Alfaro Águila-ReAl, J., «La nueva regulación del crédito comercial: Una lectura crítica de la Directiva y de la Ley contra la morosidad», Indret Revista para el Análisis del Derecho, núm. 3. julio, 2005.

${ }^{6}$ Arruñada, B., «La ley contra la morosidad comercial», Indret Revista para el Análisis del Derecho, núm. 3, julio, 2005 .
} 
una revisión teórica de la justificación de la existencia del crédito comercial y del concepto período de maduración de la empresa puesto que ambos elementos son los aspectos claves para describir la realidad acaecida y las causas de dichos hechos. Segundo, se realizará un análisis de los plazos de pago diferenciando dos situaciones: (a) las relaciones económicas entre los comercios detallistas respecto a sus proveedores; (b) las relaciones económicas existentes entre los restantes agentes económicos. Tercero y último, se describirán las principales conclusiones derivadas del estudio así como sus consecuencias en relación a la legislación objeto de análisis.

\section{El crédito comercial: Breve justificación teórica de su existencia}

Del análisis de los estados contables de toda clase de empresas cabe derivar que es habitual el uso de del crédito comercial o aplazamiento de pago a sus proveedores como forma de financiación a corto plazo; tanto es así que lo raro es encontrar empresas que no hagan uso de esta fórmula de financiación empresarial con independencia de su tamaño (grandes, medianas, pequeñas y microempresas) o de su sector de actividad.

Las fuentes de financiación de proveedores y acreedores, se definen como las cuentas a pagar derivadas de la financiación concedida por los diversos proveedores y acreedores de la empresa, relacionadas con las actividades de explotación (principales o habituales) de la empresa. Entre otros ejemplos significativos se pueden mencionar los créditos procedentes de las compras de bienes y servicios ofrecidos por proveedores y acreedores a corto plazo o las deudas contraídas con la Administración Pública y otros organismos públicos.

Esta fuente de financiación con proveedores y acreedores a corto plazo tiene dos rasgos característicos relevantes: es automática y es espontánea. ${ }^{7}$ Su carácter espontáneo deriva del hecho de que no precisan de un contrato; su naturaleza espontánea deriva del hecho, relevante a los efectos del presente trabajo, de la ausencia de un coste de financiación o interés, al menos de forma explícita. Precisamente estas dos características han supuesto que se conviertan en fuentes de financiación flexibles así como que los retrasos en el pago no supongan un coste financiero para la empresa deudora.

El escaso coste financiero de esta forma de financiación hace necesario y relevante desarrollar una política de cobros y pagos adecuada a fin de optimizar la gestión financiera de la entidad por dos motivos. ${ }^{8}$ Primero, obtener los recursos financieros necesarios para el desarrollo de la actividad productiva y/o comercial de la entidad económica. Segundo, a fin de obtener una optimización de los recursos financieros que maximice la rentabilidad de la empresa a través de la disminución del coste financiero de sus fuentes de financiación. ${ }^{9}$ En este sentido las empresas, especialmente las de tamaño mediano y grande, desarrollan su propia política con proveedores y acreedores que se define como la selección de la mejor combinación de precios, descuentos por pronto pago, calidad y variedad de productos y servicios. ${ }^{\text {IO }}$

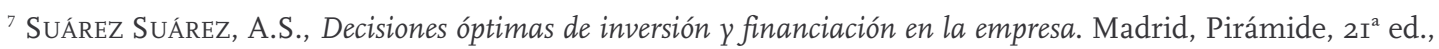
2005 .

${ }^{8}$ Brealey, R.A. y Myers, S.C., Principios de finanzas corporativas, Madrid, MacGraw-Hill, $7^{a}$ ed., 2003.

${ }^{9}$ Fuentes de financiación que se presentan en el pasivo corriente (deudas con vencimiento no superior a I2 meses) del balance de situación elaborado al cierre del ejercicio económico (generalmente a 3I de diciembre).

ro Jiménez Caballero, J.L., Pérez lópez, C. y Torre Gallegos, A., Gestión financiera de la empresa, Madrid, Pirámide, 2003.
} 
Para explicar el uso intensivo del crédito comercial, existen diversas teorías, las cuales han sido resumidas en la Tabla 3. Tal como señalan, ${ }^{\text {II }}$ existen tres grandes razones: (a) ventajas financieras; (b) discriminación de precios entre diversos mercados; (c) reducción de los costes de transacción.

TABLA 3: RAZONES DEL USO INTENSIVO DEL CRÉDITO COMERCIAL

\begin{tabular}{|c|c|c|}
\hline Motivo & Autores clave & Idea principal \\
\hline Ventajas de financiación & Schwarth (I974) & $\begin{array}{l}\text { El crédito comercial se convierte } \\
\text { en la única fuente de } \\
\text { financiación sin coste explícito } \\
\text { para la empresa }\end{array}$ \\
\hline Discriminación de precios & $\begin{array}{l}\text { Meltzer (I960); Schwartz y } \\
\text { Whitcomb (I979); Brennan, } \\
\text { Maksimovic y Zechner (I988); } \\
\text { Mian y Smith (I992) }\end{array}$ & $\begin{array}{l}\text { La existencia de plazos de pago } \\
\text { permite comercializar productos } \\
\text { similares, o con pequeñas } \\
\text { diferencias, en diferentes } \\
\text { mercados y a distintos precios }\end{array}$ \\
\hline $\begin{array}{l}\text { Reducción de costes de } \\
\text { transacción }\end{array}$ & Ferris (I98I) & $\begin{array}{l}\text { Al ser una fuente de } \\
\text { financiación espontánea no } \\
\text { requiere un contrato }\end{array}$ \\
\hline
\end{tabular}

Fuente: Adaptado de Petersen y Rajan (I997)

A modo de conclusión de este epígrafe, se puede afirmar que el aplazamiento del pago de las deudas es un elemento esencial en los mercados que permite superar algunas imperfecciones existentes en el funcionamiento de los mismos; de acuerdo con Ross, Weterfield y Jaffe el aplazamiento de pago permite: ${ }^{\text {I2 }}$

a) Facilitar la realización de intercambios económicos de bienes y servicios puesto que el cliente puede comprobar la calidad de los bienes adquiridos así como el cumplimiento del contrato.

b) Paliar las deficiencias y dificultades estructurales de los mercados financieros a la hora de financiar operaciones a corto plazo.

c) Reducir los costes de adquisición -bajo el supuesto de ausencia de morosidadpor su influencia en el precio de venta del bien; en este sentido, el aplazamiento de pago suele dar lugar, contra lo que parece intuitivo, a menores costes de adquisición.

\section{El período medio de maduración: Concepto económico esencial para medir y gestionar los plazos de pago a proveedores}

Desde una perspectiva financiera, el período medio de maduración (o PMM) se define como el tiempo que, por término medio, transcurre entre el pago por la adquisición

\footnotetext{
${ }^{\text {II }}$ Petersen, M. y RAJAN, R., «Trade credit: Theories and evidence», Review of Financial Studies, vol. IO, I997, págs. 66I-69I.

${ }^{12}$ Ross, S.A, WeTERFIELD, R.W. y JAFFE, J.F., Finanzas corporativas, Madrid, MacGraw-Hill, 7 a edición, 2005.
} 
de las materias primas a los proveedores y el cobro de la venta de los productos a los clientes. Por tanto, el período medio de maduración significa el tiempo -expresado en díasque transcurre, como promedio anual, entre que salen las unidades monetarias de la tesorería de la empresa a través del pago a los proveedores hasta que vuelven a ésta, incluido el correspondiente margen comercial, mediante el cobro de las ventas realizadas.

El cálculo del período medio de maduración de una empresa productora ha sido sintetizado en la Tabla 4. Para su comprensión, el lector debe tener presente que cada ciclo económico del capital circulante está formado por las siguientes actividades relacionadas en orden secuencial (pensado para una empresa fabricante o transformadora):

- compra de materias primas

- almacenamiento de las materias primas

- pago a proveedores

- realización del proceso productivo

- almacenamiento de los productos terminados

- venta de las mercaderías a los clientes

- cobro de los bienes y servicios comercializados

Tabla 4: Estimación del Período Medio de Maduración PARA UNA EMPRESA TRANSFORMADORA

\begin{tabular}{|c|c|c|}
\hline Período medio & Descripción & Cálculo \\
\hline \multirow[b]{2}{*}{$\begin{array}{l}\text { Almacenamiento } \\
\text { (PMA) }\end{array}$} & \multirow{2}{*}{$\begin{array}{l}\text { Es el tiempo en días que, por término } \\
\text { medio, está la materia prima en el almacén } \\
\text { de la empresa desde que se recibe de los } \\
\text { proveedores (devengo de la deuda de la } \\
\text { empresa con éstos) hasta que entra en el } \\
\text { proceso productivo }\end{array}$} & $\begin{array}{l}\text { Consumo medio diario = } \\
\text { Consumo medio anual } / 365\end{array}$ \\
\hline & & $\begin{array}{c}\text { PMA = Existencias medias de } \\
\text { materias primas / Consumo } \\
\text { medio diario }\end{array}$ \\
\hline \multirow{2}{*}{ Fabricación (PMF) } & \multirow{2}{*}{$\begin{array}{l}\text { Es el tiempo que transcurre entre la entrada } \\
\text { de los factores en producción hasta que } \\
\text { salen en forma de producto acabado }\end{array}$} & $\begin{array}{l}\text { Coste medio de la producción } \\
\text { diaria = Coste producción anual } \\
\qquad / 365\end{array}$ \\
\hline & & $\begin{array}{c}\mathrm{PMF}=\text { Existencias medias de } \\
\text { productos en curso de } \\
\text { fabricación / Coste medio de la } \\
\text { producción diaria }\end{array}$ \\
\hline \multirow{2}{*}{ Venta (PMV) } & \multirow{2}{*}{$\begin{array}{l}\text { Abarca desde que un producto terminado } \\
\text { entra en almacén tras haber acabado su } \\
\text { proceso productivo hasta el momento de su } \\
\text { venta (con el consiguiente devengo de la } \\
\text { deuda por parte del cliente) }\end{array}$} & $\begin{array}{l}\text { Coste medio de los productos } \\
\text { terminados vendidos } \\
\text { diariamente }=\text { Coste de los } \\
\text { productos terminados vendidos } \\
\text { anualmente } / 365\end{array}$ \\
\hline & & $\begin{array}{c}\text { PMV }=\text { Existencias medias de } \\
\text { productos terminados / Coste } \\
\text { medio de los productos } \\
\text { terminados vendidos } \\
\text { diariamente }\end{array}$ \\
\hline
\end{tabular}




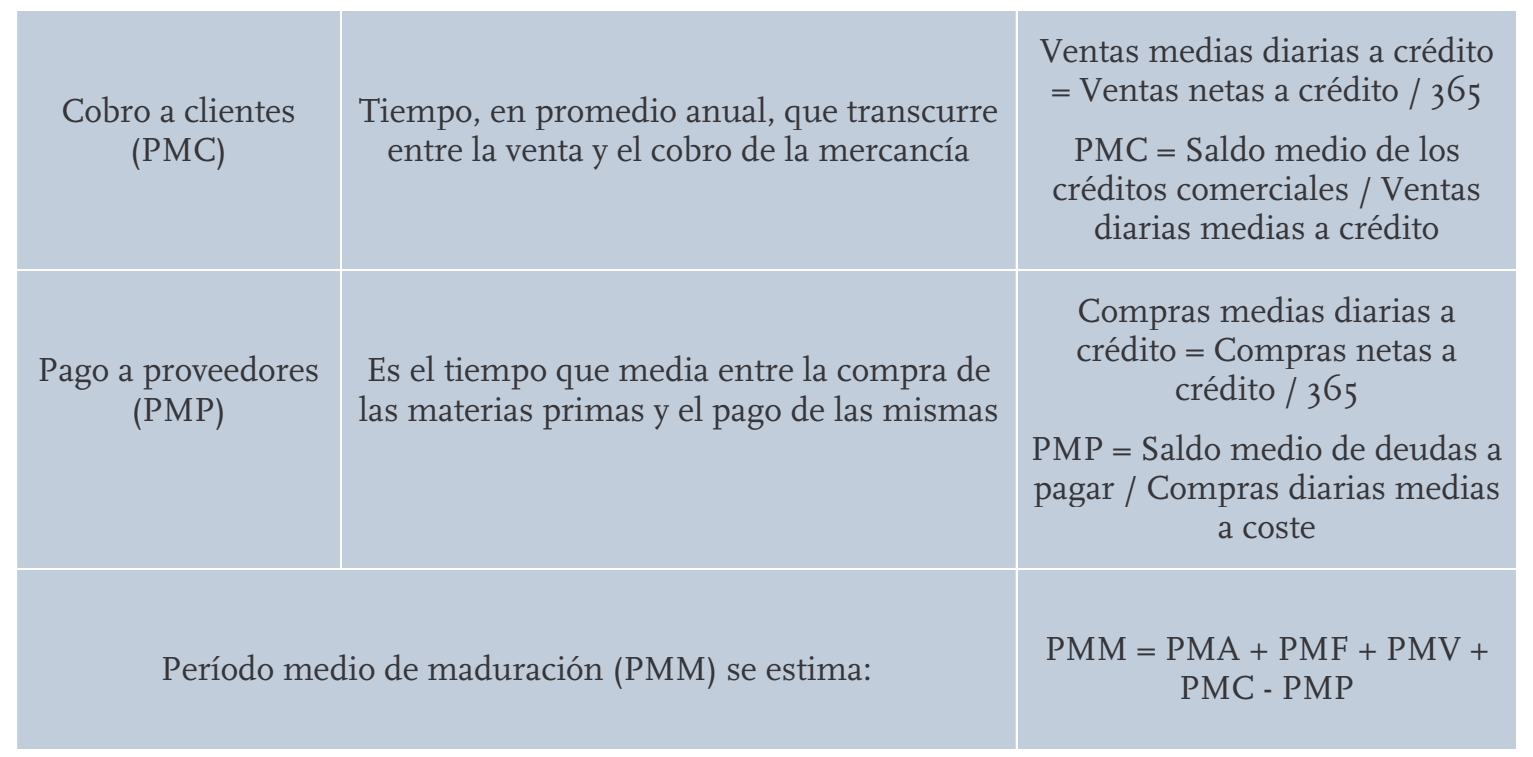

Fuente: Adaptado de Amat (2005)

El periodo medio de maduración ha sido sintetizado en el Gráfico i. Para su elaboración se ha seguido la nomenclatura indicada en la Tabla 4 por lo que PMA, PMF, PMV, PMC y PMP significan respectivamente los plazos medios de almacenamiento, fabricación, venta, cobro a clientes y pago a proveedores. Cada uno de estos plazos corresponde al tiempo promedio anual entre dos etapas del ciclo económico:

a) El plazo medio de almacenamiento (PMA) abarca el intervalo de tiempo comprendido entre la entrega de las materias primas por los proveedores $\left(\mathrm{M}_{\mathrm{I}}\right)$ y su posterior entrada en el proceso productivo $\left(\mathrm{M}_{2}\right)$.

b) El plazo medio de fabricación (PMF) refleja el intervalo temporal comprendido entre la entrada de las materias primas al proceso productivo $\left(\mathrm{M}_{2}\right)$ y su posterior salida de dicho proceso de fabricación tras haber sido elaborados los productos que comercializa la empresa $\left(\mathrm{M}_{4}\right)$.

c) El plazo medio de pago a proveedores (PMP) abarca el intervalo de tiempo comprendido entre la entrega de las materias primas por los proveedores $\left(\mathrm{M}_{\mathrm{I}}\right)$ y su posterior pago de las facturas $\left(\mathrm{M}_{3}\right)$.

d) El plazo medio de venta (PMV) refleja el intervalo temporal comprendido entre la entrada en almacén de los productos terminados $\left(\mathrm{M}_{4}\right)$ y su posterior salida tras haber sido vendidos $\left(\mathrm{M}_{5}\right)$.

e) El plazo medio de cobro a clientes (PMC) abarca el intervalo de tiempo comprendido entre la entrega de las mercancías a los clientes $\left(\mathrm{M}_{5}\right)$ y su ulterior cobro de la deuda adquirida por éstos $\left(\mathrm{M}_{6}\right)$.

f) El período medio de maduración refleja el tiempo promedio de financiación del ciclo económico por lo cual abarca el intervalo temporal existente entre la salida de fondos de la empresa derivados del pago de las materias primas adquiridas $\left(\mathrm{M}_{3}\right)$ hasta el momento en que se cobran las deudas de los clientes $\left(\mathrm{M}_{6}\right)$. Es fácil observar que un alargamiento del plazo de pago implica unas menores necesidades de financiación del ciclo económico para la entidad. 


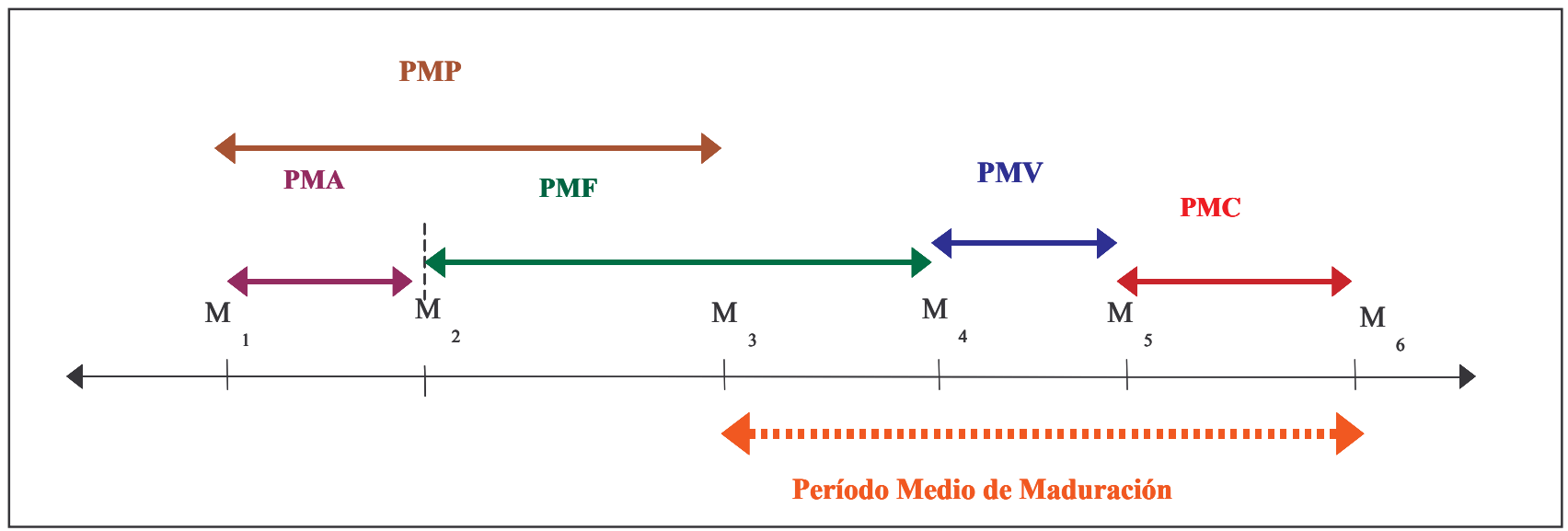

A efectos del presente trabajo, es interesante explicitar que el período medio de maduración de una empresa de distribución comercial es algo diferente (véase la Tabla 5). Económicamente, la principal diferencia entre una empresa productiva y otra de naturaleza comercial (distribución mayorista y/o minorista) radica en que las primeras tienen un proceso productivo a través del cual transforman las materias primas adquiridas en otros productos diferentes, los cuales son posteriormente comercializados. Sin embargo, las empresas de distribución compran y venden los mismos bienes y servicios por lo cual su actividad se resume exclusivamente en tres plazos: almacenamiento de productos terminados, cobro de las ventas a los clientes y pago de las mercaderías a los proveedores.

\section{TABla 5: Estimación del Período Medio de MAduración PARA UNA EMPRESA DE DISTRIBUCIÓN COMERCIAL}

\begin{tabular}{|c|c|c|}
\hline Período medio & Descripción & Cálculo \\
\hline Venta (PMV) & $\begin{array}{l}\text { Es el tiempo en días que, por término } \\
\text { medio, está la materia prima en el almacén } \\
\text { de la empresa desde que se recibe de los } \\
\text { proveedores (devengo de la deuda de la } \\
\text { empresa con éstos) hasta que es vendida a la } \\
\text { clientela de la entidad }\end{array}$ & $\begin{array}{l}\text { Coste medio de los productos } \\
\text { vendidos diariamente }=\text { Coste } \\
\text { de los productos vendidos } \\
\text { anualmente / } 365 \\
\text { PMV = Existencias medias de } \\
\text { productos / Coste medio diario } \\
\text { de los productos vendidos }\end{array}$ \\
\hline $\begin{array}{l}\text { Cobro a clientes } \\
\qquad(\mathrm{PMC})\end{array}$ & $\begin{array}{l}\text { Tiempo, en promedio anual, que transcurre } \\
\text { entre la venta y el cobro de la mercancía }\end{array}$ & $\begin{array}{l}\text { Ventas medias diarias a crédito } \\
=\text { Ventas netas a crédito / } 365 \\
\text { PMC = Saldo medio de los } \\
\text { créditos comerciales / Ventas } \\
\text { diarias medias a crédito }\end{array}$ \\
\hline $\begin{array}{l}\text { Pago a proveedores } \\
\qquad(\mathrm{PMP})\end{array}$ & $\begin{array}{l}\text { Es el tiempo que media entre la compra de } \\
\text { los productos y su pago }\end{array}$ & $\begin{array}{c}\text { Compras medias diarias a } \\
\text { crédito = Compras netas a } \\
\text { crédito / } 365 \\
\text { PMP = Saldo medio de deudas a } \\
\text { pagar / Compras diarias medias } \\
\text { a coste }\end{array}$ \\
\hline
\end{tabular}


Fuente: Adaptado de Amat (2005)

A fin de ilustrar los conceptos anteriores, se ha preparado el siguiente ejemplo. Sea un puesto de venta de refrescos abierto todos los días del año. El pasado año vendió un total de I6.500 latas de refresco a un precio de I,5€ por unidad; el precio de compra de dichas latas a sus proveedores fue de $0,36 €$ la unidad siendo las compras anuales también de I6.500 latas. Adicionalmente, se saben los siguientes datos: (a) el valor medio de las existencias ascendió a $360 €$; (b) el saldo medio de clientes fue de $300 €$; (c) la deuda media con proveedores era de $200 €$. De acuerdo con los datos anteriores y, por tratarse de una empresa de distribución comercial, se aplican los conceptos recogidos en la Tabla 5 por tratarse de una empresa comercial. Los resultados finales serían los siguientes:

$\left.\mathrm{I}^{\circ}\right)$ El plazo medio de venta fue de 22,I2 días.

$2^{\circ}$ ) El plazo medio de cobro a clientes era 82,5 días.

$\left.3^{\circ}\right)$ El plazo medio de pago a proveedores fue de 12,29 días.

$4^{\circ}$ ) El período medio de maduración resultante fue 91,98 días. Dicho valor se ha obtenido como suma de los plazos medios de venta y de cobro a clientes, restando al importe resultante el plazo medio de pago a proveedores.

A la vista de los datos anteriores, podemos afirmar que la empresa anterior necesita obtener financiación, bien a través de fondos propios bien a través del endeudamiento con terceros, para financiar la actividad durante 9I,98 días. Suponiendo que las ventas se repartieran de forma homogénea a lo largo del ejercicio económico, aunque lo lógico sería que existiera una fuerte estacionalidad de la demanda de refrescos con su momento cima durante los meses de verano, por lo que habría que financiar la adquisición de 4.I58 latas de refresco (prorrateo de las I6.500 latas que se compran anualmente para los 9I,98 días de período de maduración). Esto significa que los fondos a obtener para que la actividad económica pueda llevarse a cabo suponen I.496,88 euros, los cuales equivalen al 25,2\% de las compras anuales. En definitiva, aunque el negocio sea rentable existen posibles tensiones de tesorería para que la actividad empresarial pueda llevarse a cabo sin incidencias negativas siendo el período medio de maduración el concepto que habitualmente mide este hecho. Por consiguiente, no debe confundirse las exigencias de financiación con la rentabilidad de la actividad económica desarrollada aunque las dificultades de tesorería para afrontar pagos tienen siempre incidencia negativa sobre las fuentes de financiación futuras de la empresa.

En definitiva, el período medio de maduración constituye una medida del dinamismo de la actividad de una empresa por dos motivos:

$\left.\mathrm{I}^{\circ}\right)$ Si el período medio de maduración es corto supone un elevado ritmo de funcionamiento, produciéndose varias veces el ciclo de actividad durante el ejercicio económico; el número de veces que se repite el ciclo se denomina «rotación», siendo su valor el inverso de cada uno de los plazos medios expuestos en las Tablas 4 y 5 en función del tipo de empresa.

$2^{\circ}$ ) Si el período medio de maduración es largo significa que la rotación es baja, lo cual implica mayores necesidades de financiación con costes más elevados. 
Como norma general, se puede afirmar que cuanto menor sea el período medio de maduración aumenta la eficiencia de la gestión empresarial. Por el contrario, una deficiente gestión de dicho período medio de maduración provoca importantes tensiones financieras a las empresas por lo que es conveniente implementar todas las medidas oportunas para que este ciclo sea lo más pequeño posible. En este sentido, es muy importante señalar a los efectos del presente trabajo que, a diferencia de lo que ocurre con los demás plazos medios, a la empresa le interesa aumentar el período medio de pago a proveedores.

¿Puede darse la circunstancia de que el período medio de maduración sea negativo (por ejemplo, PMM = - 20 días)? Efectivamente, podría ocurrir este hecho lo cual significaría que la empresa recibe las mercancías, desarrolla totalmente su proceso productivo y de comercialización, cobra las mercancías vendidas y, pasados tantos días como indica en términos absolutos el montante calculado, paga a los proveedores las mercancías vendidas. En el ejemplo anterior, un período negativo medio de 20 días significa que la empresa ha retenido como promedio anual el importe monetario equivalente a 20 días de las compras diarias a proveedores en su poder por lo que ha estado financiando su actividad a través del crédito comercial concedido por las empresas que la aprovisionan los diferentes insumos que adquiere.

No obstante, el hecho de que el período medio de maduración sea negativo ha de ser interpretado con cuidado puesto que pues puede ser provocado por dos tipos de situaciones claramente opuestas (véase el Gráfico 2). Primera, podría ocurrir que una empresa tenga sistemáticamente escasez de recursos monetarios con el subsiguiente retraso en los pagos; ello daría lugar a un mayor intervalo temporal del plazo de pago a proveedores y, por tanto, puede generar un acortamiento del período medio de maduración e incluso que éste sea negativo. En este contexto se podría afirmar que el período medio de maduración negativo ha de ser interpretado como reflejo de una empresa con problemas de liquidez. Segunda, también puede darse una situación aparentemente paradójica: las empresas definen una política de cobros y pagos en la que tratan sistemáticamente de retrasar los pagos a sus proveedores como han hecho tradicionalmente en España los comercios minoristas de alimentación y de otros productos de gran consumo-. En este caso, el período medio de maduración negativo significaría que dichas empresas consideran más ventajoso financiarse a través del crédito comercial (además de poder pactar estas condiciones con sus proveedores) puesto que éste sería más barato que la financiación tradicional a través de los diversos instrumentos de financiación ofertados por las entidades financieras, ya sean bancarias o no bancarias. En definitiva, ha de quedar claro que alargamiento de los plazos de pago y morosidad son dos conceptos diferentes que no han de ser confundidos pero que se basan ambos en un amplio plazo medio de pago a proveedores.

\section{GRÁFICO 2: PERÍODO MEDIO DE MADURACIÓN Y MOROSIDAD DE LAS EMPRESAS}

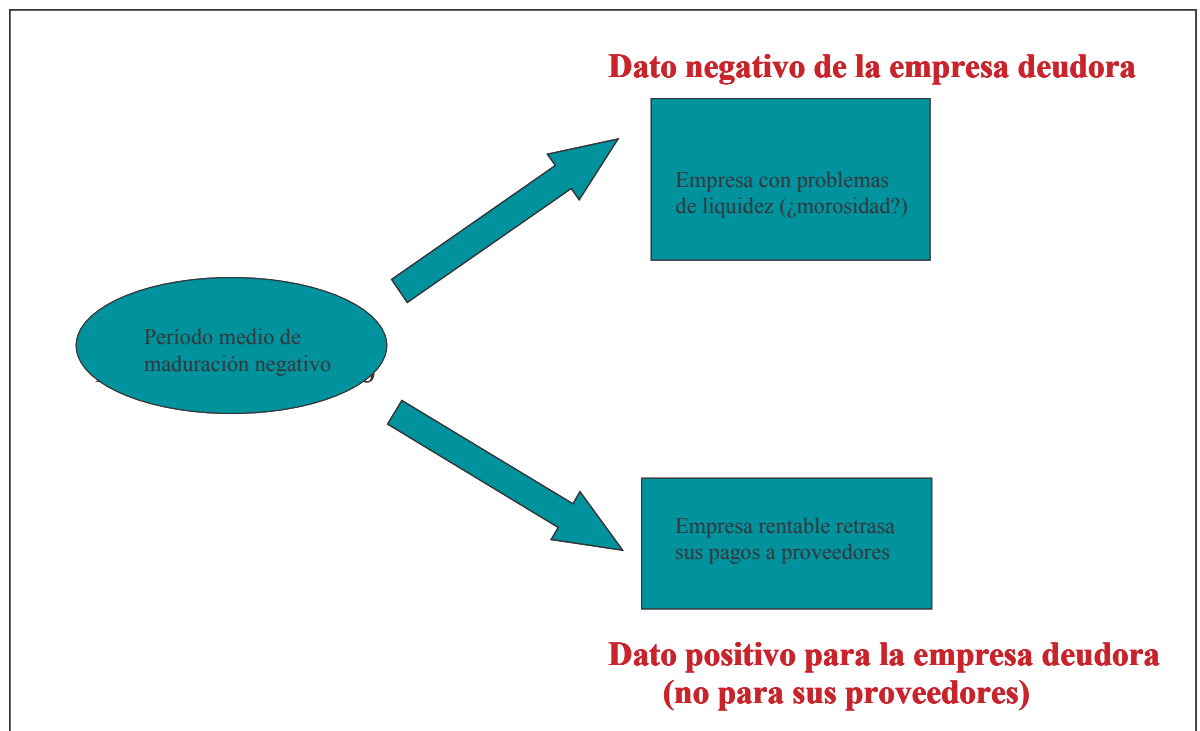




\section{Pago a proveedores por las empresas comerciales minoristas}

En el presente epígrafe se analizará el efecto de la promulgación de la Ley 3/2004 sobre el plazo medio de pago de las empresas de distribución comercial detallista a sus proveedores. Para ello, se ha considerado adecuado analizar la situación previa a la entrada en vigor de la Ley para conocer la situación de partida; a continuación, se mostrará la evolución de los plazos de pago del comercio detallista; finalmente, se analizarán los principales motivos que pueden explicar la situación existente.

El primer aspecto a tener en cuenta es la coexistencia de situaciones muy heterogéneas dentro del ámbito geográfico de la Unión Europea, los cuales responden a unas pautas muy específicas (véase la Tabla 6). En los países nórdicos existe un plazo medio de pago muy corto, que se va agrandando progresivamente al recorrer de Norte a Sur el territorio comunitario. Los países con mayor plazo medio de pago dentro de la UE son los países latinos, siendo España e Italia los dos países con mayor retraso en el pago del crédito comercial por parte del comercio detallista a los fabricantes que los aprovisionan de mercancías. $^{\text {I3 }}$

El segundo aspecto a resaltar es que en nuestro país existe una suave tendencia a reducir el pago de pago a proveedores a partir del año I993 ${ }^{\mathrm{I4}}$ con la excepción de las empresas hosteleras, las cuáles pagaban como media Ioo días después de recibir las mercancías a sus proveedores en el año $2000 .^{\mathrm{I5}}$

TABla 6: PlaZo MEdio de PAGo Y PERIOdO MEDIO DE MADURACIÓN PARA LAS PRINCIPALES EMPRESAS COMERCIALES MINORISTAS EN EL CONTEXTO EUROPEO (2004)

\begin{tabular}{|c|c|c|c|}
\hline \multirow{2}{*}{ País } & Empresa & Plazo medio de pago & $\begin{array}{c}\text { Período medio de } \\
\text { maduración }\end{array}$ \\
\hline \multirow{3}{*}{ España } & Carrefour & I24 & -97 \\
\hline & Alcampo & II2 & -69 \\
\hline & Eroski & IO7 & -77 \\
\hline & Mercadona & 82 & -59 \\
\hline Dia & Lidl & 83 & -73 \\
\hline Francia & Carrefour & 58 & -58 \\
\hline & Alcampo & 66 & -15 \\
\hline
\end{tabular}

${ }^{13}$ Román GonZÁlez, M.V., «Situación del aplazamiento de pago en España: un análisis comparativo en el ámbito europeo», Boletín Económico de Información Comercial Española, núm. 2645, 2006, págs. 25-34.

${ }^{14}$ Melle Hernández, M., «La actividad financiera de las grandes superficies. Caracterización de sus modelos de comportamiento», Perspectivas del Sistema Financiero, vol. 57, I997, págs. II-39.

${ }^{15}$ Román GonZÁlez, M.V., «Análisis comparativo de los plazos de pago en la industria alimentaria y en la distribución comercial», Información Comercial Española, núm. 739, I995, págs. 93-Io9. RoMÁN GonZÁLEZ, M.V. Evolución de los plazos de pago. Comparativa internacional, Colección de Estudios de Comercio Interior, núm. 70, Madrid, Ministerio de Comercio y Turismo, 200I. 


\begin{tabular}{|c|c|c|c|}
\hline & Casino & 69 & -22 \\
\hline & Leclerc & $4^{2}$ & $-I$ \\
\hline \multirow{3}{*}{ Bélgica } & Carrefour & 57 & -15 \\
\hline & Delhaize & 59 & -4 \\
\hline & Colruyt & $5^{\mathrm{I}}$ & $-\mathrm{I} 4$ \\
\hline \multirow{2}{*}{ Portugal } & Carrefour & 65 & - I7 \\
\hline & Jerónimo Martins & 59 & -9 \\
\hline \multirow{3}{*}{ Alemania } & Rewe & 25 & 26 \\
\hline & Edeka Ava & 50 & 26 \\
\hline & Spar Handel & $3 \mathrm{I}$ & IO \\
\hline
\end{tabular}

Fuente: Elaboración propia a partir de los datos contables presentados en el Registro Mercantil (o entidad similar en otros países).

El tercer elemento significante es el hecho de que son las empresas de distribución comercial de mayor tamaño (grandes cadenas de supermercados y de hipermercados) quienes tienen un mayor plazo de pago en la UE, lo cual va asociado a un elevado y negativo período medio de maduración. Por ejemplo, Carrefour tenía en 2004 el mayor retraso en el pago a sus proveedores en España, Bélgica y Portugal (véase la tabla 6) y los datos expuestos apuntan a una estrategia financiera de retraso en los pagos a fin de financiarse mediante la deuda a corto plazo derivada del crédito comercial concedido por sus proveedores.

De forma similar a la comparación de los plazos medios de pagos entre empresas de distribución comercial que operan en ciertos países significativos de la Unión Europea mostrada en la Tabla 6 , se ha realizado un análisis de los plazos medios de cobro y de pago de las principales entidades detallistas radicadas en España para el período I996-2003 (véase la Tabla 7). Sintéticamente, las empresas con un plazo medio de pago más elevado antes de la entrada en vigor de la Ley 3/2004 eran Carrefour (I2I días en promedio entre la recepción de la mercancía y el desembolso de la compra realizada), Eroski (II3 días), Alcampo (iıo días), El Corte Inglés (94 días), $\mathrm{Dia}^{\mathrm{I}}{ }^{\mathrm{a}}$ (87 días), Mercadona (86 días) y Sabeco (78 días). En definitiva, los principales grupos de distribución comercial radicados en España han desarrollado una política de expansión del negocio para posicionarse de forma ventajosa en el conjunto del territorio nacional basada en la financiación a corto plazo que les proporcionaban sus proveedores mediante el crédito comercial. ${ }^{17}$

\footnotetext{
${ }^{16}$ Distribuidora Internacional de Alimentación (Dia) es una empresa de tiendas de descuento cuya propiedad y control están ligados a Carrefour. De manera similar, Sabeco es una cadena de supermercados pequeños vinculada a Alcampo.

${ }^{17}$ Cruz Roche, I., Fernández, A., Rebollo Arévalo, A., «Estrategia de aplazamiento de pago en las empresas de distribución de alimentación», Perspectivas del Sistema Financiero, vol. 57, I997, págs. 45-57. Casares Ripol, J., Rebollo Arévalo, A., Distribución comercial, Madrid, Thomson-Civitas, $3^{\text {a }}$ ed., 2005.
} 
TABla 7: Plazos DE PAGo Y DE COBRo EN LA DistRibUCión ESPAÑOLA (I996-2003)

\begin{tabular}{|c|c|c|c|c|c|c|c|c|c|}
\hline \multirow{2}{*}{ EMPRESAS } & \multirow{2}{*}{ MAGNITUD } & \multicolumn{8}{|c|}{ ANOS } \\
\hline & & 2003 & 2002 & 2001 & 2000 & 1999 & 1998 & 1997 & 1996 \\
\hline \multirow{3}{*}{ AHOLD } & Plazos Cobro & * & 8 & 91 & 23 & 109 & 448 & * & * \\
\hline & Plazos Pago & * & 86 & 28 & 121 & 154 & * & * & * \\
\hline & Diferencia & * & 78 & -63 & 98 & 45 & * & * & * \\
\hline \multirow{3}{*}{ AHORRAMAS SA } & Plazos Cobro & 53 & 41 & 44 & 52 & 48 & 48 & 50 & * \\
\hline & Plazos Pago & 71 & 64 & 57 & 68 & 73 & 73 & 80 & * \\
\hline & Diferencia & 17 & 23 & 13 & 17 & 25 & 25 & 30 & * \\
\hline \multirow{3}{*}{ ALCAMPO SA } & Plazos Cobro & 14 & 15 & 16 & 13 & 14 & 16 & 28 & * \\
\hline & Plazos Pago & 110 & 103 & 110 & 109 & 108 & 113 & 111 & * \\
\hline & Diferencia & 96 & 88 & 95 & 96 & 94 & 97 & 83 & * \\
\hline \multirow{3}{*}{ CAPRABO SA } & Plazos Cobro & 7 & 5 & 4 & 3 & 4 & 5 & 4 & * \\
\hline & Plazos Pago & 75 & 76 & 72 & 68 & 79 & 75 & 81 & * \\
\hline & Diferencia & 68 & 70 & 68 & 65 & 75 & 70 & 77 & * \\
\hline \multirow{3}{*}{$\begin{array}{r}\text { CENTROS COMERCIALES } \\
\text { CARREFOUR SA }\end{array}$} & Plazos Cobro & 27 & 30 & 35 & 22 & 19 & 17 & 9 & * \\
\hline & Plazos Pago & 121 & 118 & 100 & 111 & 136 & 125 & 128 & * \\
\hline & Diferencia & 94 & 88 & 65 & 89 & 117 & 108 & 119 & * \\
\hline \multirow{3}{*}{$\begin{array}{r}\text { CONDIS SUPERMERCATS, } \\
\text { S.A. }\end{array}$} & Plazos Cobro & 62 & 51 & 48 & 42 & 43 & 53 & 51 & * \\
\hline & Plazos Pago & 61 & 56 & 60 & 64 & 74 & 65 & 66 & * \\
\hline & Diferencia & -1 & 5 & 13 & 21 & 31 & 12 & 15 & * \\
\hline \multirow{3}{*}{ CONSUM S COOP V } & Plazos Cobro & * & 12 & 16 & 15 & 16 & 12 & 9 & 18 \\
\hline & Plazos Pago & * & 100 & 110 & 107 & 115 & 116 & 111 & 121 \\
\hline & Diferencia & * & 89 & 94 & 93 & 99 & 104 & 102 & 103 \\
\hline \multirow{3}{*}{$\begin{array}{l}\text { DISTRIBUIDORA } \\
\text { INTERNACIONAL DE } \\
\text { ALIMENTACIÓN SA }\end{array}$} & Plazos Cobro & 6 & 8 & 9 & 8 & 9 & 9 & 11 & ${ }^{*}$ \\
\hline & Plazos Pago & 87 & 85 & 82 & 86 & 87 & 88 & 83 & * \\
\hline & Diferencia & 81 & 78 & 73 & 78 & 78 & 79 & 72 & * \\
\hline \multirow{3}{*}{$\begin{array}{r}\text { DISTRUBUCIÓN MERCAT } \\
\text { SA }\end{array}$} & Plazos Cobro & 4 & 6 & 19 & 35 & * & * & * & * \\
\hline & Plazos Pago & 79 & 85 & 88 & * & * & * & * & * \\
\hline & Diferencia & 75 & 80 & 69 & * & * & * & * & * \\
\hline \multirow{3}{*}{ EI CORTE INGLES SA } & Plazos Cobro & 41 & 34 & 48 & 46 & 50 & 54 & 66 & * \\
\hline & Plazos Pago & 94 & 90 & 92 & 92 & 97 & * & 76 & * \\
\hline & Diferencia & 52 & 56 & 43 & 46 & 47 & * & 10 & * \\
\hline \multirow{3}{*}{$\begin{array}{r}\text { EROSKI SOC. } \\
\text { COOPERATIVA LIMITADA } \\
\text { DE CONSUMO }\end{array}$} & Plazos Cobro & 26 & 23 & 19 & 21 & 19 & 20 & 15 & * \\
\hline & Plazos Pago & 113 & 114 & * & 116 & 126 & * & * & * \\
\hline & Diferencia & 88 & 90 & * & 96 & 107 & * & * & * \\
\hline \multirow{3}{*}{$\begin{array}{l}\text { GRUPO EL ARBOL } \\
\text { DISTRIBUCIÓN Y } \\
\text { PERMERCADOS SA }\end{array}$} & Plazos Cobro & 6 & 9 & 7 & 15 & 15 & 10 & 12 & * \\
\hline & Plazos Pago & 78 & 60 & 61 & 59 & 71 & 64 & 91 & * \\
\hline & Diferencia & 71 & 51 & 54 & 44 & 56 & 54 & 79 & * \\
\hline \multirow{3}{*}{ HIPERCOR, S.A. } & Plazos Cobro & 2 & 6 & 4 & 2 & 3 & 4 & 4 & * \\
\hline & Plazos Pago & 33 & 52 & 56 & 56 & 58 & 60 & 67 & * \\
\hline & Diferencia & 30 & 45 & 52 & 53 & 55 & 56 & 63 & * \\
\hline \multirow{3}{*}{ LIDL SUPERMERCADOS SA } & Plazos Cobro & * & 1 & 1 & 2 & 1 & 2 & 2 & 2 \\
\hline & Plazos Pago & * & 61 & 62 & 84 & 71 & 80 & 60 & 78 \\
\hline & Diferencia & * & 60 & 61 & 83 & 70 & 78 & 58 & 76 \\
\hline \multirow{3}{*}{ MERCADONA SA } & Plazos Cobro & 3 & 3 & 3 & 5 & 6 & 5 & 3 & * \\
\hline & Plazos Pago & 86 & 87 & 89 & 82 & 79 & 77 & 69 & * \\
\hline & Diferencia & 83 & 84 & 86 & 77 & 73 & 72 & 66 & * \\
\hline & Plazos Cobro & * & 4 & 5 & 7 & 10 & 5 & 7 & * \\
\hline - & Plazos Pago & * & 96 & 99 & 104 & 107 & 103 & 99 & * \\
\hline & Diferencia & * & 91 & 94 & 97 & 97 & 98 & 92 & * \\
\hline & Plazos Cobro & * & 12 & 15 & 15 & 16 & 13 & 17 & 16 \\
\hline SABECO SA & Plazos Pago & * & 78 & 79 & 87 & 82 & 76 & 78 & 77 \\
\hline & Diferencia & * & 66 & 63 & 71 & 66 & 63 & 61 & 61 \\
\hline
\end{tabular}

* Información no disponible 
Fuente: Casado y Román (2007)

La evolución del plazo medio de pago de las empresas de distribución comercial detallista radicadas en España ha sido recogida en el Gráfico 3. De su análisis se desprenden varias ideas. Primero, se refrenda el elevado retraso entre el momento de recepción de las mercancías y el pago de las mismas realizado sistemáticamente por las empresas minoristas. Segundo, ha existido un primer momento de caída de dicho plazo durante el trienio 2000-02 para posteriormente volver a incrementarse el plazo medio de pago hasta 86,7 días en 2004. Tras la entrada en vigor de la Ley 3/2003 se ha producido una caída sostenida del plazo de pago hasta los 7I,5 días de demora media durante 2007 .

\section{GRÁfico 3: PlAZO MEDio de PAGO EN EL COMERCIO DETALLISTA ESPAÑOL (I995-2007)}

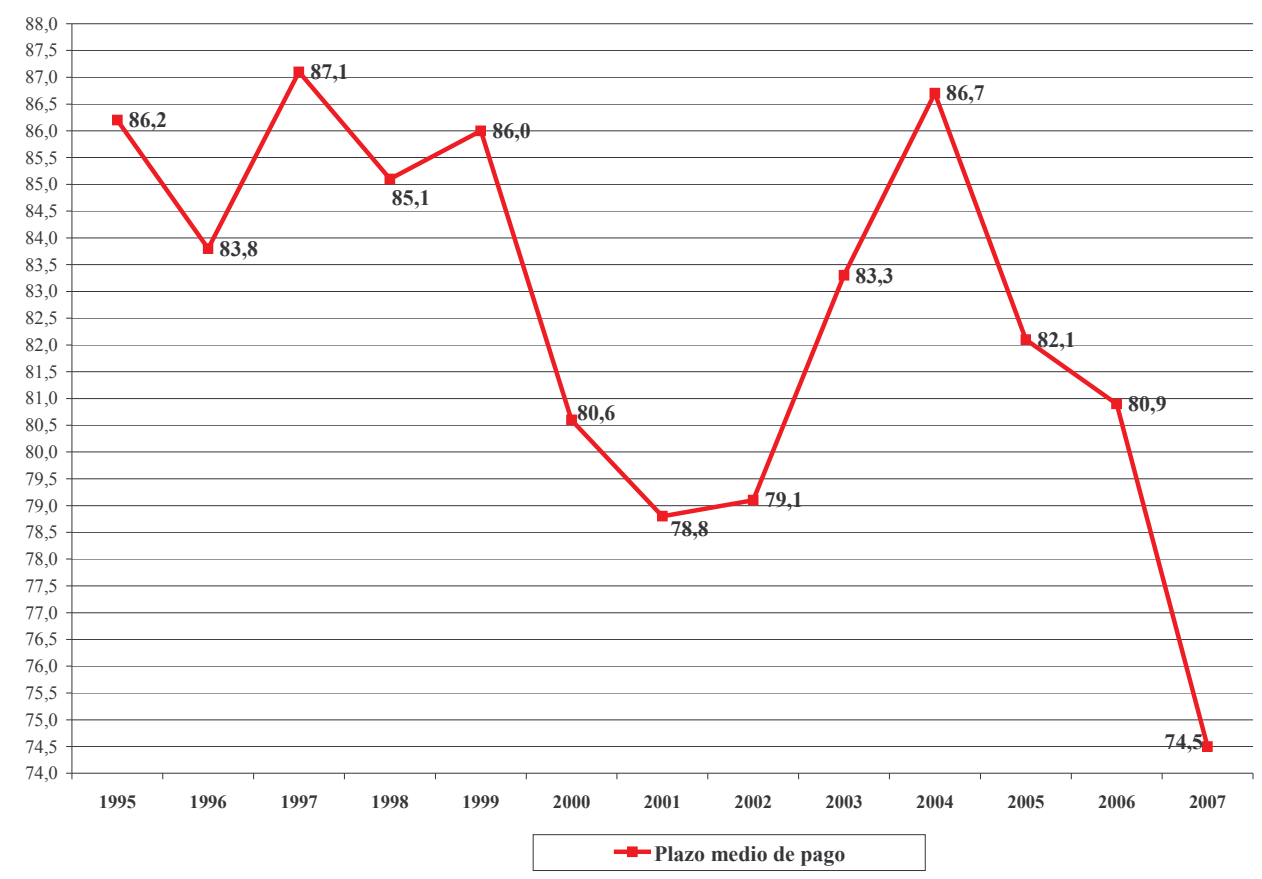

Fuente: Secretaría de Estado de Turismo y Comercio

La Tabla 8 muestra el plazo medio de pago de algunas significativas empresas detallistas radicadas en nuestro país durante los dos últimos años. Las dos ideas más sobresalientes de dichas magnitudes son las siguientes: (a) se ha producido en todos los casos una reducción del plazo de pago a proveedores, acorde con la evolución general mostrada en el gráfico 3; (b) dicha reducción se ha realizado de forma asimétrica puesto que las empresas de capital español lo han realizado de forma más intensa que las empresas de origen francés. 
TABLA 8: PlAZOS DE PAGO DE EMPRESAS DETALLISTAS ESPAÑOLAS RELEVANTES TRAS LA ENTRADA EN VIGOR DE LA LEY 3/2004

\begin{tabular}{|c|c|c|}
\hline Empresas/Año & $\mathbf{2 0 0 6}$ & $\mathbf{2 0 0 7}$ \\
\hline Alcampo & 95 & 94 \\
\hline Carrefour & 105 & 96,7 \\
\hline Mercadona & 76 & 64 \\
\hline Eroski & 85 & 68 \\
\hline
\end{tabular}

Fuente: Elaboración propia a partir de los datos contables presentados en el Registro Mercantil

¿Cuáles son las principales causas subyacentes a los hechos descritos? En nuestra opinión, se pueden señalar tres motivos básicos. En primer lugar, la reducción del número de establecimientos detallistas (véase la Tabla 9), hecho que se viene produciendo de forma constante desde I975, implica un aumento de la intensidad competitiva de los fabricantes para lograr tener un espacio en los lineales de los distribuidores; para lograrlo, han utilizado diversas políticas comerciales, en especial la reducción de márgenes y el mayor aplazamiento del pago, a fin de lograr que su oferta fuera más atractiva para los comercios detallistas con los que negociaban.

TABLA 9: EVoluCión DEL NÚMERO DE ESTABLECIMIENTOS DETALLISTAS EN ESPAÑA ${ }^{18}$

\begin{tabular}{|c|c|c|c|c|c|c|c|}
\hline Tipología & $\mathbf{2 0 0 2}$ & $\mathbf{2 0 0 3}$ & $\mathbf{2 0 0 4}$ & $\mathbf{2 0 0 5}$ & $\mathbf{2 0 0 6}$ & $\mathbf{2 0 0 7}$ \\
\hline Tradicionales & 33.452 & 31.617 & 29.532 & 28.198 & 27.423 & 26.746 \\
\hline LS $<100 \mathrm{~m}^{2}$ & 12.177 & 11.576 & 10.973 & 10.586 & 10.305 & 10.095 \\
\hline $100<\mathrm{SS}<400 \mathrm{~m}^{2}$ & 8.032 & 7.811 & 7.502 & 7.367 & 7.591 & 7.812 \\
\hline $\begin{array}{c}\text { Supermercados } \\
\text { pequeños }\end{array}$ & 3.801 & 4.027 & 4.147 & 4.261 & 4.397 & 4.465 \\
\hline $\begin{array}{c}\text { Supermercados } \\
\text { grandes }\end{array}$ & 1.342 & 1.539 & 1.742 & 1.913 & 2.096 & 2.298 \\
\hline $\begin{array}{c}\text { Hipermercados } \\
\left(<2.500 \mathrm{~m}^{2}\right)\end{array}$ & 332 & 343 & 359 & 365 & 379 & 387 \\
\hline Total & $\mathbf{5 9 . 0 7 6}$ & $\mathbf{5 6 . 9 1 3}$ & $\mathbf{5 4 . 2 5 5}$ & $\mathbf{5 2 . 6 9 0}$ & $\mathbf{5 2 . 1 9 1}$ & $\mathbf{5 1 . 8 1 2}$ \\
\hline
\end{tabular}

Fuente: Adaptado de Nielsen (2008)

\footnotetext{
${ }^{18}$ Los establecimientos detallistas se clasifican según la superficie de su zona de ventas, contada desde la línea de cajas de pago hacia el interior del punto de venta, de la siguiente manera: (a) Tiendas tradicionales: establecimientos en régimen de venta personal tradicional; (b) establecimientos de libre servicio o LS: superficie de venta inferior a roo metros cuadrados; (c) Superservicio o SS: superficie destinada a la venta comprendida entre 100 y 399 metros cuadrados; (d) Supermercados pequeños: puntos de venta cuya zona de ventas está comprendida entre 400 y 999 metros cuadrados; (e) Supermercados grandes: establecimientos detallistas cuya sala de ventas está comprendida entre I.000 metros cuadrados y 2.499 metros cuadrados; (f) Hipermercados: puntos de venta cuya zona dedicada a la venta supera los 2.500 metros cuadrados.
} 
Un segundo motivo adicional, ha sido el mayor peso económico de las empresas de distribución comercial de mayor tamaño en relación con la dimensión económica de los fabricantes que les proveen de bienes y servicios. Mientras que el sector productivo ha estado relativamente atomizado, con un predominio de empresas familiares y de pymes, la concentración ha experimentado un proceso de concentración ya que un número relativamente pequeño de establecimientos y/o de empresas realizan la mayor parte de las ventas (véase la Tabla Io). Por ejemplo, durante 2007 en España, de acuerdo con los datos proporcionados por la empresa Nielsen, el $2 \%$ de los puntos de venta detallistas han vendido el $42 \%$ de las ventas totales a los consumidores y unidades familiares residentes en nuestro país. De hecho, las cadenas de hipermercados y de supermercados, pequeños y grandes, suponían el 70,0\% de las ventas de productos de gran consumo en 2004, porcentaje que ha crecido hasta el $74,5 \%$ en el año $2007 .{ }^{19}$

TABLA IO: EVOLUCIÓN DE LA CUOTA DE MERCADO DEL COMERCIO MINORISTA POR FORMATOS COMERCIALES EN ESPAÑA

\begin{tabular}{|c|c|c|c|c|c|c|c|}
\hline Tipología & $\mathbf{2 0 0 2}$ & $\mathbf{2 0 0 3}$ & $\mathbf{2 0 0 4}$ & $\mathbf{2 0 0 5}$ & $\mathbf{2 0 0 6}$ & $\mathbf{2 0 0 7}$ \\
\hline Tradicionales & 6,5 & 5,9 & 5,5 & 5,1 & 4,8 & 4,4 \\
\hline $\mathrm{LS}<100 \mathrm{~m}^{2}$ & 6,8 & 6,4 & 5,9 & 5,6 & 5,3 & 4,8 \\
\hline $100<\mathrm{SS}<400 \mathrm{~m}^{2}$ & 20,2 & 19,8 & 18,5 & 17,6 & 17,3 & 16,4 \\
\hline $\begin{array}{c}\text { Supermercados } \\
\text { pequeños }\end{array}$ & 20,7 & 21,9 & 22,1 & 21,5 & 21,1 & 20,8 \\
\hline $\begin{array}{c}\text { Supermercados } \\
\text { grandes }\end{array}$ & 17,6 & 20,3 & 23,3 & 26,2 & 28,3 & 31,2 \\
\hline $\begin{array}{c}\text { Hipermercados } \\
\left(<2.500 \mathrm{~m}^{2}\right)\end{array}$ & 28,2 & 25,7 & 24,6 & 23,9 & 23,2 & 22,5 \\
\hline
\end{tabular}

Fuente: Adaptado de Nielsen (2008)

El tercer motivo es la coexistencia de dos tipos de negocios en el comercio detallista, afirmación que debe ser acotada exclusivamente a los principales grupos de distribución comercial minorista españoles en función de su tamaño, es decir, según su cifra de facturación anual. Lógicamente, el «negocio tradicional» es el que proviene de la compraventa de mercancías a las que se aplica un margen de beneficios de origen comercial. Adicionalmente, las principales empresas detallistas tienen un período medio de maduración negativo lo cual significa que como promedio tienen entre dos y tres meses el dinero de sus proveedores. Estos fondos monetarios suponen unas cuantías muy elevadas y suelen ser invertidas por los respectivos departamentos financieros dando lugar a un «negocio financiero» que, en épocas de altos tipos de interés ha dado rentabilidades superiores a las procedentes del negocio comercial tradicional..$^{20}$ De acuerdo con la Tabla II, en promedio un hipermercado facturó en España 44,38 millones durante el año 2007; de forma análoga, la cifra de ventas promedio anual de los supermercados pequeños y grandes españoles fue de 2,22 y de 6,80 millones de euros respectivamente. Realizando un pequeño

${ }^{19}$ Los datos anteriores han sido obtenidos a partir de los anuarios de evolución del comercio detallista español que realiza Nielsen, cuyo último número citado ha sido incluido en la bibliografía del presente estudio.

${ }^{20}$ Cruz Roche, I., Yagüe Guillén, M.J., Rebollo Arévalo, A. y Oubiña Barbolla, J., «Concentración y competencia en la distribución minorista en España», Información Comercial Española, núm. 779, julio-agosto, I999, págs. 9-36. 
supuesto como podría ser que un hipermercado tuviera una rentabilidad financiera anual del $4 \%$ y que el plazo medio de pago fuera 72 días ${ }^{21}$, significaría que obtendría una rentabilidad de 2,22 millones de euros derivada del negocio comercial $^{22}$ y de 1,78 millones de euros procedente del negocio financiero.

TABLA II: EVOLUCIÓN DE LA CUOTA DE MERCADO DEL COMERCIO MINORISTA POR

\begin{tabular}{|c|c|c|c|}
\hline 2007 & $\begin{array}{c}\text { Número de } \\
\text { establecimientos }\end{array}$ & $\begin{array}{c}\text { Ventas anuales por } \\
\text { punto de venta (miles } \\
\text { de euros) }\end{array}$ & $\begin{array}{c}\text { Ventas anuales por } \\
\text { metro cuadrado de } \\
\text { superficie de venta }\end{array}$ \\
\hline Supermercados pequeños & 2.298 & 2.217 & 3.353 \\
\hline Supermercados grandes & 4.465 & 6.804 & 4.627 \\
\hline Hipermercados & 387 & 44.380 & 5.867 \\
\hline
\end{tabular}

Fuente: Adaptado de Nielsen (2008)

Los tres motivos anteriores dibujan en conjunto un panorama en el cual las principales cadenas de distribución comercial han planificado y ejecutado planes estratégicos enfocados a una intenso y rápido proceso de crecimiento empresarial con la doble finalidad de expandir su cifra de ventas y su cuota de mercado puesto que ello genera un negocio comercial atractivo. Adicionalmente, también ha generado un negocio financiero derivado de la financiación de inversiones a largo plazo mediante el (barato) crédito comercial a corto plazo de sus proveedores. La evolución temporal de este proceso ha significado un traspaso del poder y control en el canal de distribución de los fabricantes a los distribuidores (véase la Tabla I2). Este es el motivo subyacente al proceso descrito: las empresas detallistas de cierto tamaño no han tratado únicamente de financiarse a través de sus proveedores sino que les han transferido parte del riesgo de negocio a través de la dependencia financiera de los fabricantes respecto a las organizaciones comerciales mencionadas. En definitiva, se trata de una lucha por el poder y el control en el canal de distribución puesto que, una vez más, se cumple la máxima de que quien controla el canal de distribución (los grupos detallistas) obtiene beneficios adicionales de su posición competitiva ventajosa a costa de aquellos agentes económicos que dependen de aquellos (las empresas proveedoras y productivas). ${ }^{23}$

\footnotetext{
${ }^{21}$ De forma prudente, se ha estimado una cuantía equivalente al plazo medio en España durante 2007 aunque las cadenas de hipermercados tienen en realidad plazos mayores de pago, lo cual significaría que las cifras obtenidas estarían infravalorando el negocio financiero.

${ }^{22}$ El margen comercial se ha estimado a partir de la media del sector, medida como el beneficio antes de impuestos respecto a la cifra de ventas anual.

${ }^{23}$ Casares Ripol y Rebollo Arévalo, Distribución comercial, cit.
} 
TABLA I2. PODER Y CONTROL EN EL CANAL DE DISTRIBUCIÓN

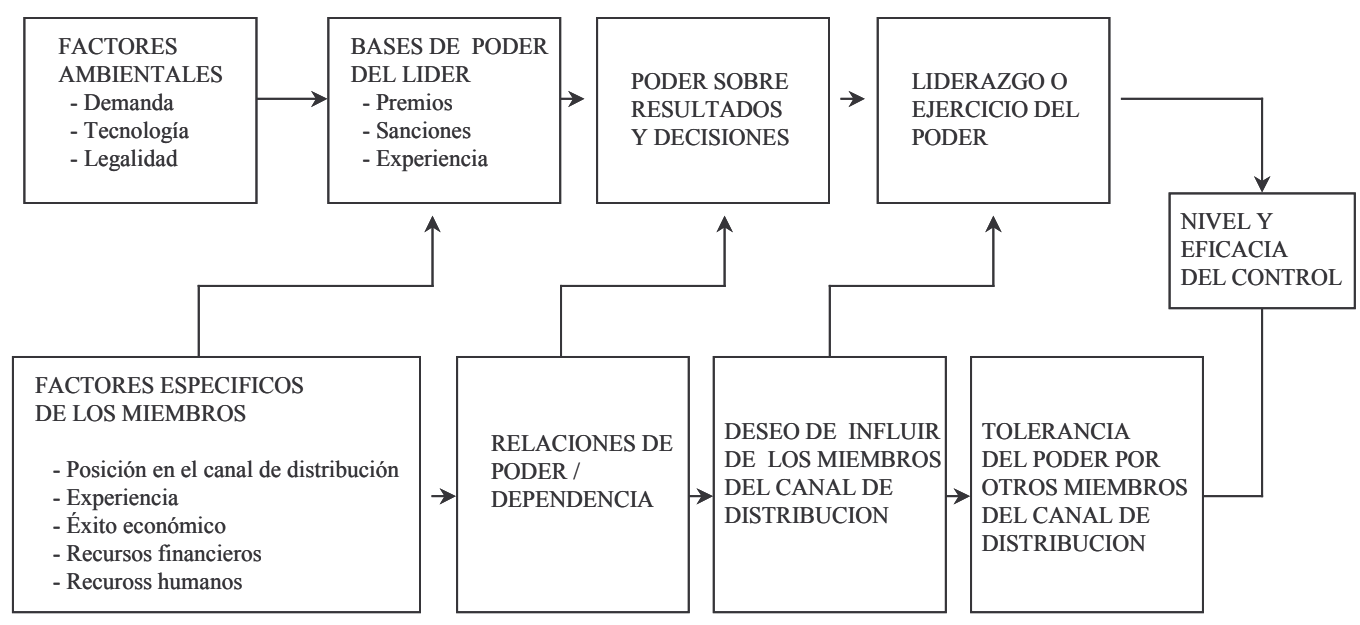

Fuente: Adaptado de Vázquez y Trespalacios (2006)

\section{Plazos de pago de los restantes agentes económicos}

Tras analizar la problemática de las relaciones fabricante-distribuidor en lo referente a los plazos medios de pago, se procederá a realizar un análisis similar para los restantes agentes económicos, sean éstos de naturaleza privada o de titularidad pública.

A fin de ofrecer una visión sintética de lo acaecido en España tras la promulgación de la Ley 3/2004, se ha desglosado la información en tres categorías, relativas a cada uno de los grandes tipos de agentes económicos aún no citados en el presente trabajo (véase el Gráfico 4). De un lado, se ha reflejado la información relativa al conjunto de las Administraciones y empresas de titularidad pública; de otro lado, se ha recogido la información referente al sector privado pero, dada su diferente problemática, se ha separado al sector de la construcción del resto de sectores económicos. 
GRÁFICO 4: EVOLUCIÓN DEL PLAZO MEDIO DE PAGO

EN EL SECTOR PÚBLICO Y PRIVADO ESPAÑOL (2004-2007)

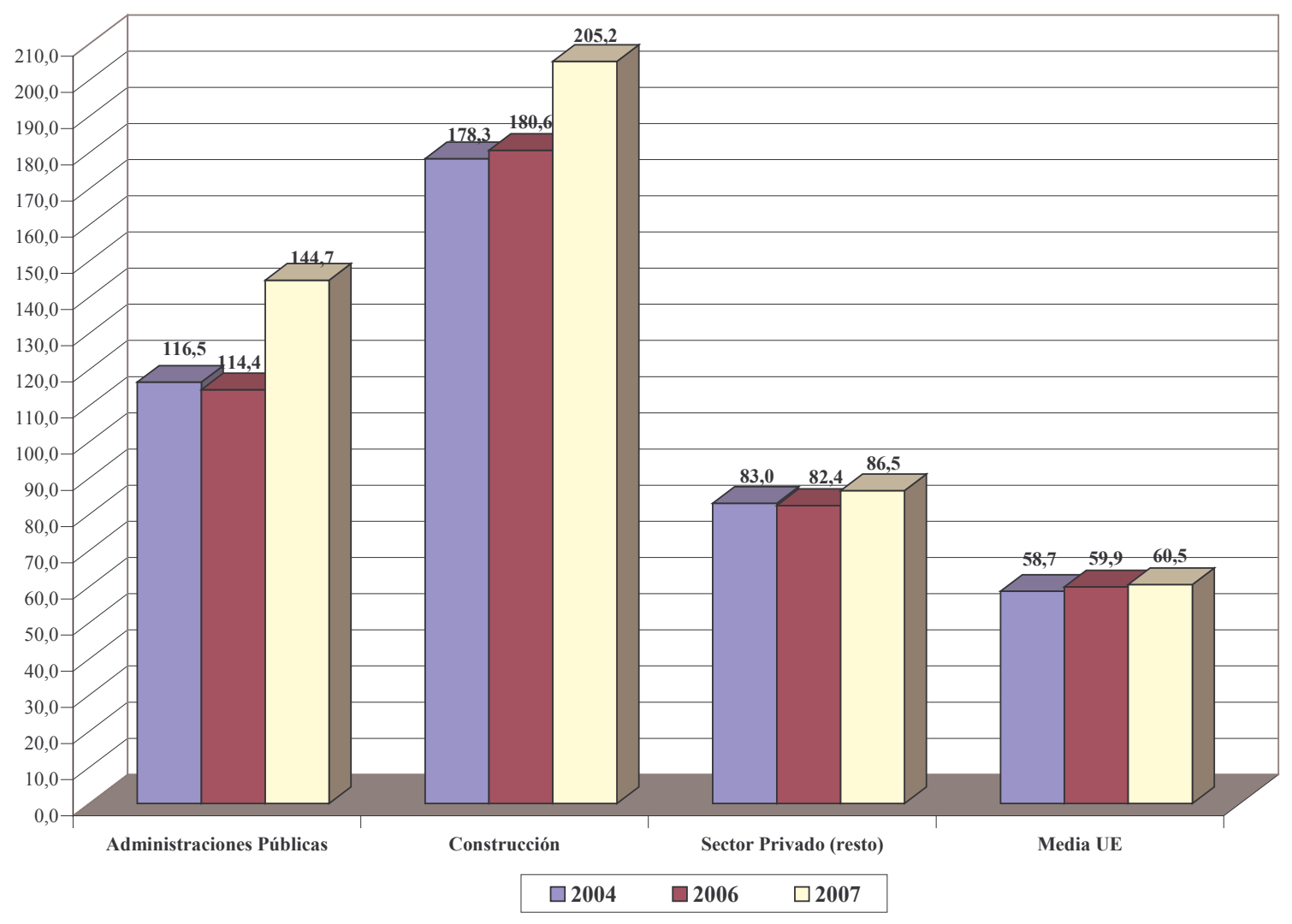

Fuente: Elaboración propia

En lo referente a las administraciones públicas, los resultados mostrados son cuando menos sorprendentes. En el año 2004 el período medio de pago del sector público a sus proveedores era de II 6,5 días pero desde entonces dicho plazo, en lugar de reducirse, se ha visto incrementado hasta I44,7 días durante 2007. Además, los plazos medios de pago son aún más altos en las operaciones del sistema sanitario que, por su propia naturaleza, son de cuantías muy elevadas. Por consiguiente, las propias entidades públicas no cumplen lo regulado en la legislación actual vigente.

En cuanto al sector público, coexisten dos situaciones diferentes. El sector de la construcción, al igual que lo indicado para las administraciones públicas, ha visto aumentado el período medio de pago desde los I78,3 días (en 2004) hasta los 205,2 días (dato relativo al año 2007). Evidentemente, la dependencia de las administraciones públicas del subsector de obra pública ha sido el detonante de este hecho, lo cual también muestra una realidad que evoluciona en sentido contrario respecto a los objetivos de legislador en la Ley 3/2004. Por último, los restantes sectores económicos han evolucionado de una forma relativamente estable; desde 2004 el plazo medio de pago se ha mantenido en unos niveles sustancialmente más bajos sufriendo un leve aumento durante el último año $(86,5$ días de plazo medio de pago).

En definitiva, el Gráfico 2 muestra una evolución de los plazos de pago en sentido contrario a lo pretendido en la Ley 3/2004. Además, en todos los sectores analizados los plazos medios de pago siguen siendo muy elevados, siendo especialmente relevante el incumplimiento de la ley tanto por las propias administraciones públicas como en sus relaciones con el sector de la construcción. 
El último elemento objeto de análisis en el presente estudio se refiere al impacto de los nuevos elementos introducidos por la Ley 3/2004 en los contratos de compraventa entre los diferentes agentes económicos antes mencionados. Dichos efectos se pueden sintetizar en tres ideas: ${ }^{24}$

$\mathrm{I}^{\circ}$ ) Solamente el $24 \%$ de los contratos ha introducido cláusulas de intereses de demora en caso de retraso en los pagos más allá de la fecha pactada entre comprador y vendedor.

$2^{\circ}$ ) Únicamente el $4,3 \%$ de los contratos han incorporado cláusulas relativas a indemnizaciones derivadas de la posible morosidad respecto a la fecha de pago pactada.

$\left.3^{\circ}\right)$ Derivado de las crecientes dificultades económicas existentes en el panorama económico actual, se está produciendo un preocupante aumento del número de operaciones comerciales que sufren retrasos en los pagos hasta el punto de que se supere la cifra de 90 días entre el momento de la venta y el ulterior momento de cobro de la deuda comercial. Tal como recoge el Gráfico 5, mientras que en el año 2006 el 19,2\% de las operaciones comerciales se cobraron con un retardo superior a 90 días, durante el pasado año dicha cifra creció hasta el 26,1\%

\section{GRÁFICO 5: EVOLUCIÓN DEL RETARDO EN LOS PAGOS (2006-2007)}

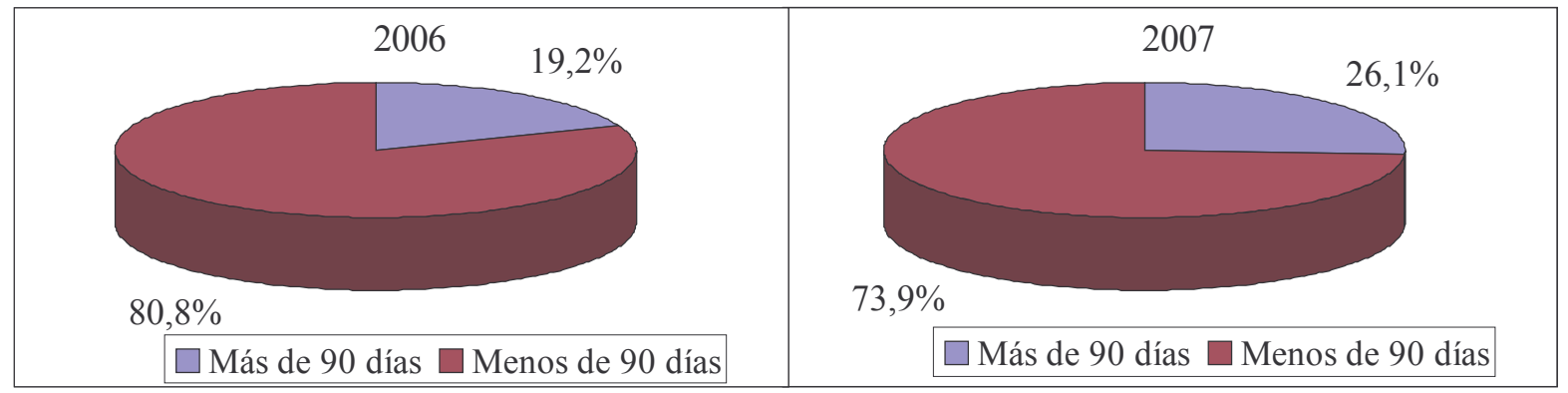

Fuente: Brachfield (2008)

\section{Conclusiones}

Del presente estudio se pueden extraer diversas conclusiones. Primera, los plazos de pago fijados en la Ley 3/2004 son ampliamente superados en los contratos pactados entre las partes desde 2005 hasta la actualidad. Segunda, las Administraciones Públicas son quienes más tardan en pagar a sus proveedores, situación que cuando menos debe ser calificada como pintoresca; adicionalmente, el sector de la construcción es donde se producen los aplazamientos de pago más elevados. Tercera, la entrada en vigor de la Ley antes citada ha significado una reducción de los plazos medios de pago por parte de la distribución comercial. Cuarto, las cláusulas de intereses de demora y de indemnizaciones, que constituían una significativa novedad de los contenidos de la Ley 3/2004, han sido poco utilizadas por parte de las empresas afectadas. Por tanto, el efecto económico de la nueva legislación se puede calificar como limitado e insuficiente al no cumplirse los plazos de pago fijados en la normativa y que, no debe olvidarse, era un objetivo esencial del legislador.

Entre los motivos de uso insuficiente de los mecanismos previstos en la Ley 3/2004 se pueden citar varios: (a) el profundo desconocimiento de la legislación por parte

\footnotetext{
${ }^{24}$ BRACHFIELD, P.J., La lucha contra la morosidad, Barcelona, Gestión 2000, 2008.
} 
de las pequeñas y medianas empresas; (b) el riesgo percibido de pérdida de clientes por parte de los proveedores debido a que la aplicación de la nueva legislación podría enturbiar las relaciones con sus clientes; (c) la existencia de criterios de pago por parte de las empresas, priorizando los desembolsos con las Aministraciones Públicas, con las entidades financieras y con sus proveedores estratégicos; (d) la posibilidad de que el acortamiento del plazo de pago desencadene vías económicas complementarias; en este sentido, algunas empresas detallistas están pagando a plazos no superiores a 30 días ciertos productos a sus proveedores pero a cambio de obtener un descuento por pronto pago de cuantía elevada, que oscilan entre el 8 y el ı०\% del importe de la operación, lo cual desincentiva al proveedor a negociar un plazo de cobro inferior al que ha sido usual en el pasado.

\section{Bibliografía}

AlBeRT, R. y CABRILlo, F., «Un análisis económico de la reforma concursal española», Revista Valenciana de Economía y Hacienda, núm. II, 2004, págs. II3-I32.

AlFARO ÁGUILA-REAL, J., «La nueva regulación del crédito comercial: Una lectura crítica de la Directiva y de la Ley contra la morosidad», Indret Revista para el Análisis del Derecho, núm. 3, julio, 2005.

AmAT, O., Análisis económico-financiero, Barcelona, Gestión 2000, 2005.

ARRUÑADA, B., «La ley contra la morosidad comercial», Indret Revista para el Análisis del Derecho, número 3, julio, 2005.

Aybar ARIAS, C., CASINO MARTÍNEZ, A. y LóPEZ GRACiA, J., «La reestructuración financiera de las pymes en crisis. Endogeneidad en la elección entre vía privada y vía concursal», Investigaciones Económicas, vol. XXX, núm. I, 2006, págs. I37-I62.

BRACHFIELD, P.J., Recobrar impagados y negociar con morosos, Barcelona, Gestión 2000, 2002.

BRACHFIELD, P.J., La lucha contra la morosidad, Barcelona, Gestión 2000, 2008.

BREAley, R.A. y MYers, S.C., Principios de finanzas corporativas, Madrid, MacGraw-Hill, $7^{a}$ ed., 2003.

Brennan, M., MAKSIMOVic, V. y ZeChner, J., «Vendor financing», Journal of Finance, vol. 43, I988, págs. II27-II4I.

CASAdo Belmonte, M.P. y RomÁn GonZÁlez, V., Impacto de la nueva normativa sobre plazos de pago en el sector de la distribución minorista de alimentación en España, Universidad de Almería, Departamento de Dirección y Gestión de Empresas, documento de trabajo, 2007 .

Casares Ripol, J. y Rebollo Arévalo, A., Distribución comercial, Madrid, Thomson-Civitas, Madrid, $3^{\mathrm{a}}$ ed., 2005.

CRUz Roche, I., Los canales de distribución de productos de gran consumo. Concentración y competencia, Madrid, Pirámide, I999.

Cruz Roche, I., Fernández, A. y Rebollo Arévalo, A., «Estrategia de aplazamiento de pago en las empresas de distribución de alimentación», Perspectivas del Sistema Financiero, vol. 57, 1997, págs. 45-57. 
Cruz Roche, I., Yagüe Guillén, M.J., Rebollo Arévalo, A. y Oubiña Barbolla, J. «Concentración y competencia en la distribución minorista en España», Información Comercial Española, núm. 779, julio-agosto, 1999, págs. 9-36.

DíAZ DíAZ, B., LóPEZ GutiéRreZ, C. y TORRE Olmo, B., «Características determinantes y contenido informativo de los mecanismos de reestructuración financiera», Revista Europea de Dirección y Economía de la Empresa, vol. I4, núm. 2, 2005, págs. III-I24.

EUler HeRmes, Los plazos de pago en el sector de la construcción en Europa. Madrid, 2007.

FERRIS, J.S., «A transanction theory of trade credit use», Quaterly Journal of Economics, vol. 94, I98I, págs. 243-270.

GonZÁlez MÉndeZ, V.M. y GonZÁlEZ RodRíGUEZ, F., «Procedimientos de resolución de insolvencia financiera en España: costes de insolvencia y transferencias de riqueza», Investigaciones Económicas, vol. XXIV, núm. 2, 2000, págs. 357-384.

Jiménez Caballero, J.L., Pérez lópez, C. y Torre Gallegos, A., Gestión financiera de la empresa, Madrid, Pirámide, 2003.

LÓPEZ GUTIÉRreZ, C., GARCÍA Olalla, M. y TORRe Olmo, B., «Implicaciones financieras de la legislación concursal: Una comparativa europea», Spanish Accounting Review, vol. 9, núm. I8, julio-diciembre, 2006 , págs. III-I43.

LÓPEZ GUTIÉRREZ, C. y TORRE OlMO, B., «Costes originados por problemas de insolvencia», Partida Doble, núm. I87, abril, 2007, págs. 82-91.

MELLE HERNÁNDEZ, M., «La actividad financiera de las grandes superficies. Caracterización de sus modelos de comportamiento», Perspectivas del Sistema Financiero, vol. 57, I997, págs. II-39.

MeLTZER, A.H., «Mercantile credit, monetary policy and size of firms», Review of Economics and Statistics, vol. 42, I960, págs. 429-437.

MiAN, S., SMITH, C., «Accounts receivable management policy: Theory and evidence», Journal of Finance, vol. 47, I992, págs. 169-200.

Nielsen, Anuario 2007. La guía de los mercados de gran consumo, Madrid, Ed. A.C. Nielsen, 2008.

PERALES VISCASILLAS, M.P., La morosidad en las operaciones comerciales entre empresas. Ley 3/2004 Y Directiva 2000/35, Madrid, Thomson-Civitas, 2006.

PETERSEN, M. y RAJAN, R., «Trade credit: Theories and evidence», Review of Financial Studies, vol. I0, I997, págs. 66I-69I.

RomÁn GonZÁleZ, M.V., «Análisis comparativo de los plazos de pago en la industria alimentaria y en la distribución comercial», Información Comercial Española, núm. 739, I995, págs. 93-109.

ROMÁN GonZÁLEZ, M.V., «Situación del aplazamiento de pago en España: un análisis comparativo en el ámbito europeo», Boletín Económico de Información Comercial Española, núm. 2645, 2000, págs. 25-34. 
RomÁn GonZÁlez, M.V., Evolución de los plazos de pago. Comparativa internacional. Colección de Estudios de Comercio Interior, núm. 70, Madrid, Ministerio de Comercio y Turismo, 200I.

Ross, S.A., WeTERFIELD, R.W. y JAFFE, J.F., Finanzas corporativas, Madrid, MacGraw-Hill, $7^{a}$ ed., 2005 .

SÁnCHEZ MedinA, J.R., «Claves del desarrollo jurídico-económico de la Ley Concursal», Estrategia Financiera, núm. 255, 2008, págs. IO-I8.

SCHWARTZ, R.A., «An economic model of trade credit», Journal of Financial Quantitative Analysis, vol. 9, I974, págs. 643-657.

SChWARTZ, R.A. y WhitComb, D., «The trade credit decision», en J. Bicksler (ed.) Handbook of Financial Economics, New York, North-Holland, I979, págs. 257-273.

SuÁreZ SuÁreZ, A.S., Decisiones óptimas de inversión y financiación en la empresa, Madrid, Pirámide, $2 \mathrm{I}^{\mathrm{a}}$ ed., 2005 .

VÁZqueZ CASielles, R. y TRespalacios GuTiÉRReZ, J.A., Estrategias de distribución comercial. Diseño del canal de distribución y relación entre fabricantes y detallistas, Madrid, Thomson-Civitas, 2006. 